\title{
The Effect of Face-to-Face and non-Face-to-Face Synchronously Collaborative Writing Environment on Student Engagement and Academic Performance
}

\author{
Mengying Han ${ }^{1 *}$ \\ Yushun $\mathbf{L i}^{2}$
}

\begin{abstract}
Collaborative Writing (CW) tools such as Google Docs provide an efficient way for students to perform collaborative writing tasks. This research is based on a novel CW tool called Cooperpad, with a group awareness functionality, which continuously gathers group members' writing behaviour, analyzes and visualize their engagement intensity for group members to compare their participation with that of others. The comparative experiment is carried out in two different online learning environments: face-to-face and non-face-to-face, with an experimental group $(\mathrm{N}=72)$ and a control group $(\mathrm{N}=48)$. Through systematic data and post-test design we have examined in which environment the students showed more engagement in the group-writing task. The results showed that Cooperpad writing system is more helpful to enhance the student engagement and improve students' academic performance on certain levels in face-to-face online learning environment compared with non-face-to-face. Moreover, the student engagement was positively correlated to the academic performance. Students have a high degree of the system, which has a positive promoting effect on learning initiative and teamwork ability.
\end{abstract}

Key Words: collaborative learning, synchronously collaborative writing system of Cooperpad, student engagement, academic performance, learning environment

\section{Introduction}

In the 21 st century, Information and Communication Technology (ICT) accelerates global competition and collaboration (Dicerbo, 2012). The Partnership for the 21 st century skills also proposed that the students must have the essential skills to be successful in the life and workplace, such as innovative thinking skills, communication and collaboration skills, critical thinking and problem solving skills. With the development of information technology, exploring how technology enables learners to study more efficiently has become an important mission of educators in the $21 \mathrm{st}$ century (Fadel, Trilling \& Charles, 2009).

Computer Supported Collaborative Learning (CSCL) plays an important role in helping learners acquire knowledge, skills and improving learning effect, by combining computer technology with collaborative learning (Stahl, 2010). As a form of CSCL, Collaborative Writing (CW) is an iterative and social process that involves a group focused on a common objective that negotiates,

\footnotetext{
Postgraduate, Beijing Normal University, School of Educational Technology, China, email: mengying han@126.com

${ }^{2} \mathrm{PhD}$, Faculty of Education, School of Educational Technology, Beijing Normal University, China, email: lyshun@bnu.edu.cn
} 
coordinates, and communicates during the creation of a common document (Lowry et al., 2004). It not only improves the quality of collaborative learning, but also enhances students' ability to analyze and solve problems in the online learning environment (Yarrow et al., 2011). In recent years, Collaborative Writing $(\mathrm{CW})$ has obtained many educational researchers' interests because of its potential pedagogical benefits. However, most of the research is limited to non-real-time collaborative writing tools (such as Wiki), but it pays less attention to real-time collaborative writing tools (such as Google Docs). The CW tools often lack of behavioural analysis in the process of writing, which cannot provide effective feedback in time (Wheeler et al., 2010). Studies have shown that the real-time collaborative writing tools have the timeliness and identity of writing behaviour and writing process, which can stimulate students' group motivation and improve the learning enthusiasm (Pymm \& Hay, 2014).

But few studies have compared the effects of real-time collaborative writing in different online learning environments. More important, it is not easy for learners to cooperate effectively in online learning. (Zurita \& Nussbaum, 2010). And it often produces different learning effects in different online learning environments between face-to-face and distributed in CSCL (Mochizuk et al., 2002). Studies have shown that the impact of non-face-to-face online learning may be greater than that of face-to-face, because online learning is easy to remove irrelevant factors such as interpersonal relationship and real environment from the interaction relationship (Tran, Raikundalia \& Yang, 2006). Compared with face-to-face communication, non-face-to-face communication in CW is more helpful to promote the equal participation of learners in discussion (Warschauer, 1996) and enhance the interaction of collaborative learning (Abuseileek, 2012). From the perspective of social support (Cohen \& Wills, 1985), the design of CSCL need to fully consider the differences between face-to-face and non-face-to-face interactions to further enhance collaborative learning.

In this article, an online Synchronously collaborative writing tool with group awareness functionality called Cooperpad has been applied to create an online synchronously collaborative writing environment. The tool can analyze each group member's writing behavior and visualizes his or her behavioral engagement with a writing task (Liu Ming, 2018). The "Advanced Web Application Development" course is taken as an example to conduct empirical research, which is carried out in two different online learning environments: face-to-face and non-face-to-face.

The major highlights of our work can be described as follows:

- Can the Cooperpad tool improve collaborative student engagement in the synchronously collaborative writing environment? What is the difference in the improvement of student engagement between face-to-face and non-face-to-face?

- Can the Cooperpad tool improve students' academic performance in the synchronously collaborative writing environment? What is the relationship between student engagement and academic achievement, and how relevant is it?

- Exploring how students evaluate Cooperpad tools through face-to-face interviews?

\section{Literature Review}

In educational, CSCL involves Collaborative Writing, where "students produce a joint text by writing a piece of text each" (Bradley, Lindström, Rystedt \& Vigmo, 2010). Collaborative Writing, which consists of one or more participants modifying, by editing, and revising the text of the participants (Witney \& Smallbone, 2011), are assumed to have the potential to enhance the 
effectiveness of peer learning interactions (Wang, 2016). Collaborative Writing (CW) has been defined in many ways. One of the earliest definitions is "participants producing a shared document by engaging in substantial interaction and sharing decisions and responsibility for it (Allen, 1987)". On the other hand, it focuses on the quality of interaction in collaborative writing, stressing the context of the writing situation and the relationships of the students (Donato, 1994). Collaborative writing is an iterative and social process that involves a group focused on a common text during the creation of a common document (Lowry et al, 2004) through interactions, shared knowledge and joint decision-making throughout the whole process (Neumann \& McDonough, 2015).

Collaborative writing is underpinned by Vygotsky's sociocultural learning theory (Kuteeva, 2011), which assumes that collaboration among participants can achieve more in terms of learning benefits than individuals (Hadjerrouit, 2014). An aspect of this theory relevant to collaborative writing is the concept of the Zone of Proximal Development (ZPD), where group members use mediational means collaboratively to create, obtain, and communicate meaning (Vygotsky, 1978). By collaborating with each other, learners are able to engage in the composition process with more clarity and understanding. Students' writings were found to be more grammatically accurate (Zhila \& Parisa, 2015), organization and vocabulary (Shehadeh, 2011). In general, the students had positive perceptions of collaborative writing.

From the perspective of time dimension, there are two collaborative writing modes, non-real-time and real-time (Storch, 2005). At present, common collaborative writing tools include wiki, Google Docs and Etherpad, etc. In China, most researches are carried out on non-real-time wiki, with less exploration on real-time tools. In addition, studies have pointed out that in the process of non-realtime collaborative writing, students often have the problem of low engagement in the group-writing task (Wheeler, Yeomans \& Wheeler, 2010), and the collaborative writing effect is often not ideal. Most students often stay on the surface of browsing content and editing text, without in-depth communication and reflection between groups (Heng, Niiya \& Warschauer, 2015). The real-time collaborative writing tools have the timeliness and identity of writing behavior and writing process (Erkens et al., 2005). The participants can see the jointly edited documents synchronously, which is helpful to enhance the enthusiasm of team members in writing, to improve the sense of team belonging and collaborative student engagement (Pymm \& Hay, 2014).

From the perspective of spatial dimension, there are two modes of collaborative writing: non-faceto-face and face-to-face, that is, collaborative writing under the non-face-to-face and face-to-face online learning environments (Storch, 2005). Computer-based interaction is the premise and specific performance of collaborative writing. It is not easy for students to study effectively. Collaborative learning in face-to-face and non-face-to-face online learning environments of common tasks often produces different learning effects. Some studies have pointed out that face-toface online learning environment can reduce the loneliness brought by social network, enhance the sense of real-time and presence, and make it easier to communicate (Helms, 2014). However, some studies have also found that compared with face-to-face learning environment, non-face-to-face online learning environment can reduce the interference of complex factors such as students' interpersonal relationship, and is more conducive to promoting equal communication among learners (Chew \& Ng, 2016). In a word, it is necessary to conduct further research on real-time collaborative writing tools to explore their specific application value in different online learning environments, face-to-face and non-face-to-face. 


\section{Methodology}

This paper aims to explore the impact of Cooperpad tool, an online real-time collaborative writing system, on student engagement and academic achievement in face-to-face and non-face-to-face synchronously collaborative writing environment, and to further explore the relationship between student engagement and academic performance.

Cooperpad (Liu et al., 2013) is a web-based system that provides real-time collaborative writing environment. Its function is to support the creation and management of online writing tasks, and the creation of online documents. It can stimulate students' collaborative writing through visual data analysis.

In this study, 87 sophomore students majoring in software engineering in a university in China were selected as experimental subjects (58 male, 29 female), with an average age of 20 and balanced computer operation level. They were randomly divided into face-to-face group and non-face-to-face group. On the one hand, the face-to-face group (42 persons, 29 male and 13 female) use the Cooperpad to carry out "face-to-face" synchronously collaborative writing, that is, seats are arranged together and they use oral language to communicate, and the group chat function of the system is turned off. On the other hand, the non-face-to-face group (45 persons, 29 male, 16 female) use the Cooperpad to carry out "non-face-to-face" synchronously collaborative writing, that is, the seating order is out of order, and they only use the chat window provided by the Cooperpad to communicate with each other in different places. The experimental group and control group were randomly divided into 3 persons in each group.

Students were asked to collaboratively write a project proposal in the "Advanced Web Application Development" course in the synchronously collaborative writing environment, which required students to discuss what system they will build using the web technologies and what are the distinct features of the system. Students had unrestricted access to the Internet or their textbooks for information to complete all parts of the project proposal (at least 1000 words). Before class, students spent time on thinking about what project they are going to build, so the writing task is manageable in a two-hour time frame based on our experience. The comparative experiment based on the Cooperpad was carried out in two networked computer labs with the same conditions. One week before the experiment, the teacher introduced the related operations of the Cooperpad, and the students had a certain degree of understanding of it.

Before the experiment, the teacher publishes the pre-designed homework questions and writing templates. After the teacher introduced the topic and the requirements, the non-face-to-face group and the face-to-face group started writing at the same time in the synchronously collaborative writing environment.

During the experiment, neither the teacher nor the researcher communicated with the subject. At the end of the experiment, a semi-structured interview was conducted on 30 students (at least one in each group) in the form of face-to-face contact, conducted in a voluntary manner. The feelings of the learners using the Cooperpad were investigated, and Table 1 is an example of the interview questions. 
Table 1. an example of the interview questions

Q1. Satisfaction with the use of the collaborative writing tools for collaborative learning, such as Do you think that using the Cooperpad in the synchronously collaborative writing environment for collaborative learning can improve learning interest and learning enthusiasm? What are the reasons?

Q2. About the experience of using the collaborative writing tools to interact with peers, such as Can you express your thoughts freely in peer discussions in the Cooperpad? Do you prefer face-toface or non-face-to-face?

Q3. General questions about using the Cooperpad, such as

What do you think are the advantages and disadvantages of using the Cooperpad for collaborative learning? What suggestions do you have for using the Cooperpad to help learning or improve the system itself?

\section{Results}

At the end of the experiment, two researchers graded the students' submissions according to a scale provided by the teacher. The student engagement data recorded in the system were exported and SPSS 23.0 was used for statistical analysis. Table 2 shows the comparison results of the student engagement of the face-to-face group and the non-face-to-face group in the collaborative writing process. The average student engagement of the face-to-face group was 1131.133 , while the nonface-to-face group was 1455.644. It can be seen that the engagement of non-face-to-face groups is higher than that of face-to-face groups. The differences was significant $(t=-2.079$, sig $=0.047$, $\mathrm{p}<0.05$ ), tested using a t-test for independent samples. This indicates that in practical application, the Cooperpad can enhance the learning enthusiasm of students and improve student engagement of cooperative learning in the synchronously collaborative writing environment. Especially in the nonface-to-face online learning environment, it has more obvious effect on improving the student engagement, which further indicates that the Cooperpad is more suitable for collaborative writing in the non-face-to-face synchronously collaborative writing environment. On the one hand, this result is consistent with the Sinatra et al. (2015) study which showed that active participation is the key to effective learning, and high students' engagement will affect students' knowledge acquisition and ability improvement. On the other hand, with the non-face-to-face synchronously collaborative writing environment compared with the face-to-face, the Cooperpad frees itself from the influence of other complex factors such as interpersonal relationships, collaborative environments and helps students to communicate and interact equally (Chew \& $\mathrm{Ng}$, 2016). The interaction of information technology has always been regarded as one of the influencing factors that promote student engagement in learning (Dixson, 2010).

Table 2. student engagement analysis and $\mathrm{T}$ test results of face-to-face group and non-face-to-face 
Vol. 1, Issue 2, Dec 2019, Journal of Education, Innovation, and Communication (JEICOM), pp.65-74

DOI: https://doi.org/10.34097/jeicom-volume-1-issue-2-december-2019-5

group in the synchronously collaborative writing

\begin{tabular}{c|c|c|c|c|c}
\hline Group & $\mathrm{N}$ & Mean & $\mathrm{F}$ & $\mathrm{t}$ & $\mathrm{ES}$ \\
\hline face-to-face & 14 & 1131.133 & \multirow{2}{*}{0.046} & \multirow{2}{*}{-2.079} & .047 \\
\cline { 1 - 3 } & 15 & 1455.644 & & & \\
\hline non-face-to-face & 15 &
\end{tabular}

Table 3. bivariate correlation test results of concentration and score in the synchronously collaborative learning

\begin{tabular}{c|c|c|c}
\hline & student engagement & Number of words & Academic performance \\
\hline $\mathrm{P}$ & 1 & .240 & $.693 * *$ \\
\hline $\mathrm{ES}$ & & .210 & .000 \\
\hline $\mathrm{N}$ & 29 & 29 & 29 \\
\hline
\end{tabular}

Note: ** was at the level of 0.01 (bilateral), and the correlation was significant. $*$ at the level of 0.05 (double-tailed), the correlation was significant

To further explore the relationship between student engagement and academic performance, a bivariate correlation test was conducted. It can be seen from the data results that there is a positive correlation between student engagement and their academic performance, which is significant at the level of 0.01 (see table 3). The results showed that the enhancement of the student engagement was helpful to the academic performance, and the higher the engagement was, the higher the performance was. This conclusion is consistent with the results of previous studies, which believed that student engagement is of great help to improve academic performance and is an important factor of it (Liu et al., 2015; Liu et al., 2018).

After the interview, the information obtained from the interviewees' answers can be summarized according to the following aspects (see table 4). Most of the participants said that the Cooperpad with group awareness functionality helped them enhance their sense of belonging and actively participate in team tasks of the synchronously collaborative writing environment. They also affirmed the real-time interaction and feedback capabilities of the tool. However, several other students put forward suggestions to improve the system function: single resource, it is recommended to provide more vivid and rich information, such as pictures, audio, video, etc. Moreover, the interactive tools provided by the platform have certain limitations; In order to address those limitations it is suggested that to provide some tools for discussion such as audio and video calls.

Table 4. The interview results of the Students' perceptions of the Cooperpad.

\section{Q1: Satisfaction}

Do you think that using the Cooperpad for collaborative learning can improve learning interest and learning enthusiasm? What are the reasons?

Answer1: In group writing, we can see the writing content of other members and provide suggestions at any time.

Answer2: The ability to edit in real time creates a positive competition for to work harder at the task.

Answer3: The student engagement graph can remind us to fulfill our responsibilities. We can also see the progress of other groups and encourage the enthusiasm in our group. 


\section{Q2. Interactive preferences}

Can you express your thoughts freely in peer discussions in the Cooper pad ? Do you prefer face-toface or non-face-to-face environment?

Answer 1: Online communication makes me feel more comfortable. I use the Internet to analyze and solve problems or urge team members to complete tasks. If this kind of conversation is carried out face to face, I will feel embarrassed.

Answer 2: In the discussion, I can express what I want to say. I am very comfortable, do not care about the other party's expressions and emotions, and do not feel too embarrassed.

Answer 3: Directly edit and modify on the platform, do not need to use Microsoft Word and other software, which is very convenient.

Answer 4: There is no need to upload or send a file, or even upload or send a modified job, saving time and effort

Q3. Suggestions

What do you think are the advantages and disadvantages of using the Cooperpad for collaborative learning? What suggestions do you have for using the Cooperpad to help learning or improve the system itself?

Answer 1: The system is very simple to use, the layout of the web page is clear, you can quickly find the group work page, chat discussion area.

Answer 2: The student engagement real-time graph is very cool, just to prevent some students becoming lazy, play a certain role in supervision and motivation.

Answer 3: The learning resources are relatively simple, which are all texts. I hope to provide more vivid learning resources.

Answer 4: Sometimes, my Suggestions take a long time to be answered, and I like to communicate synchronously with my partner so that problems can be solved quickly.

Answer 5: Synchronous chat is more helpful for discussing problems, and group members can schedule a time for voice chat, which is more convenient.

\section{Discussion and Conclusion}

With the development of the Internet, new ideas, new technologies and new tools have changed our learning and life. The society has higher and higher requirements for talents in the 21 st century. The ability to solve problems through collaboration has become a basic requirement. CSCL combines collaborative learning with computer technology, focusing on the collaborative learning theory and technical design, providing a broad space for collaborative learning. It plays an important role in helping students better acquire knowledge and skills. However, most of the relevant researches are limited to the non-real-time collaborative learning field, with insufficient attention to real-time collaboration and less control over student engagement.

In this article, an online collaborative writing tool with group awareness functionality called Cooperpad is applied to create the synchronously collaborative writing environment. And the "Advanced Web Application Development" course is taken as an example to conduct empirical research, which carried out in two different synchronously collaborative writing environments: face-to-face and non-face-to-face, to evaluate the collaborative learning effect of the Cooperpad and explore its educational application value.

The experimental results show that: 
- Compared with face-to-face synchronously collaborative writing environment, the Cooperpad improves the student engagement more significantly in non-face-to-face. That is non-face-to-face synchronously collaborative writing environment can help students to get rid of the interference of other complex factors such as interpersonal relationship and real environment to a certain extent, and promote equal communication and interaction between students (Chew \& $\mathrm{Ng}, 2016$ ). Moreover, the interaction of information technology plays an important role in promoting students' active participation and collaboration (Duque \& Lola, 2014).

- There is a significant correlation between student engagement and academic performance. The higher student engagement, the higher the academic performance, which has an impact on promoting student engagement and is a key factor affecting the learning effect (Pizzimenti \& Axelson, 2015).

- The interview results show that learners have a high evaluation of such functions as real-time interaction and visual feedback provided by Cooperpad, which confirms that the tool plays a positive role in promoting students' learning enthusiasm and team cooperation ability. Some students also put forward some suggestions to improve the existing functions of it, such as resource richness and functional diversity.

In summary, this study only verified the effect of online real-time collaborative writing system on student engagement and academic performance in different synchronously collaborative writing environments, nevertheless did not further explore the influence of other factors such as group division of labor and role arrangement. Secondly, as for the measurement and evaluation of the engagement of the tool, only the behavioral engagement is considered, while the evaluation of cognitive engagement and emotional engagement is insufficient. Finally, due to browser compatibility and other reasons during the experiment, the display effect of the real-time graph may affect the experimental results.

This study introduces a new perspective for exploring the educational practice of CSCL system in different online learning environments. However, we should not only pay attention to the learning effect, but also pay attention to the influence of students' cooperative ability and engagement. This research focuses on the impact of the synchronously collaborative writing environment on student engagement and academic performance, whilst not going deep into the interactive process analysis. The Cooperpad's group mutual evaluation function provides a ground for future research.

\section{References}

AbuSeileek, A. F. (2012). The effect of computer-assisted cooperative learning methods and group size on the EFL learners' achievement in communication skills. Computers \& Education, 58(1), 231-239.

Allen, N., Atkinson, D., Morgan, M., Moore, T., \& Snow, C. (1987). What experienced collaborators say about collaborative writing. Iowa State Journal of Business and Technical Communication, 1(2), 70-90.

Bradley, L., Lindström, B., \& Rystedt, H. (2010). Rationalities of collaboration for language learning in a wiki. ReCALL, 22(2), 247-265.

Cohen, S., \& Wills, T. A. (1985). Stress, social support, and the buffering hypothesis. Psychological bulletin, 98(2), 310.

DiCerbo, K. (2014). Assessment and teaching of 21 st century skills. 
Vol. 1, Issue 2, Dec 2019, Journal of Education, Innovation, and Communication (JEICOM), pp.65-74

DOI: https://doi.org/10.34097/jeicom-volume-1-issue-2-december-2019-5

Dixson, M. D. (2010). Creating effective student engagement in online courses: What do students find engaging?. Journal of the Scholarship of Teaching and Learning, 1-13.

Donato, R. (1994). Collective scaffolding in second language learning. Vygotskian approaches to second language research, 33456.

Duque, L. C. (2014). A framework for analysing higher education performance: students' satisfaction, perceived learning outcomes, and dropout intentions. Total Quality Management \& Business Excellence, 25(1-2), 1-21.

Erkens, G., Jaspers, J., Prangsma, M., \& Kanselaar, G. (2005). Coordination processes in computer supported collaborative writing. Computers in Human Behavior, 21(3), 463-486.

Hadjerrouit, S. (2014). Wiki as a collaborative writing tool in teacher education: Evaluation and suggestions for effective use. Computers in Human Behavior, 32, 301-312.

Helms, J. L. (2014). Comparing Student Performance in Online and Face-to-Face Delivery Modalities. Journal of asynchronous learning networks, 18(1), n1.

Kuteeva, M. (2011). Wikis and academic writing: Changing the writer-reader relationship. English for Specific Purposes, 30(1), 44-57.

Liu, M., Calvo, R. A., \& Pardo, A. (2013, July). Tracer: A tool to measure and visualize student engagement in writing activities. In 2013 IEEE 13th International Conference on Advanced Learning Technologies (pp. 421-425). IEEE.

Liu, M., Calvo, R. A., Pardo, A., \& Martin, A. (2014). Measuring and visualizing students' behavioral engagement in writing activities. IEEE Transactions on learning technologies, 8(2), 215-224.

Liu, M., Liu, L., \& Liu, L. (2018). Group awareness increases student engagement in online collaborative writing. The Internet and Higher Education, 38, 1-8.

Lowry, P. B., Curtis, A., \& Lowry, M. R. (2004). Building a taxonomy and nomenclature of collaborative writing to improve interdisciplinary research and practice. The Journal of Business Communication (1973), 41(1), 66-99.

Mochizuki, T., Egi, H., Ozawa, S., Shibahara, Y., Inoshita, O., \& Kato, H. (2002, December). Analysis of relationship between face-to-face collaborative learning and CSCL activities. In International Conference on Computers in Education, 2002. Proceedings. (pp. 387-391). IEEE.

Mohammadnia, Z., \& Ayaz, P. (2015). The Effects of Guided vs. Unguided Pressured Planning on EFL Learners' Writing Fluency. English Language Teaching, 8(3), 169-176.

Neumann, H., \& McDonough, K. (2015). Exploring student interaction during collaborative prewriting discussions and its relationship to L2 writing. Journal of Second Language Writing, 27, 84-104.

Pizzimenti, M. A., \& Axelson, R. D. (2015). Assessing student engagement and self-regulated learning in a medical gross anatomy course. Anatomical sciences education, 8(2), 104-110.

Pymm, B., \& Hay, L. (2014). Using etherpads as platforms for collaborative learning in a distance education LIS course. Journal of Education for Library and Information Science, 133-149.

Shehadeh, A. (2011). Effects and student perceptions of collaborative writing in L2. Journal of Second Language Writing, 20(4), 286-305.

Sinatra, G. M., Heddy, B. C., \& Lombardi, D. (2015). The challenges of defining and mea suring student engagement in science.

Stahl, G., Koschmann, T. D., \& Suthers, D. D. (2006). Computer-supported collaborative learning . 
Vol. 1, Issue 2, Dec 2019, Journal of Education, Innovation, and Communication (JEICOM), pp.65-74

DOI: https://doi.org/10.34097/jeicom-volume-1-issue-2-december-2019-5

na.

Storch, N. (2005). Collaborative writing: Product, process, and students' reflections. Journal of second language writing, 14(3), 153-173.

Tran, M. H., Raikundalia, G. K., \& Yang, Y. (2006). Using an experimental study to develop group awareness support for real-time distributed collaborative writing. Information and Software Technology, 48(11), 1006-1024.

Trilling, B., \& Fadel, C. (2009). 21 st Century Skills.: Learning for Life in Our Times. John Wiley \& Sons.

Vygotsky, L. S. (1978). Mind in society (M. Cole, V. John-Steiner, S. Scribner, \& E. Souberman, Eds.).

Wang, D. (2016, February). How people write together now: Exploring and supporting today's computer-supported collaborative writing. In Proceedings of the 19th ACM Conference on Computer Supported Cooperative Work and Social Computing Companion (pp. 175-179). ACM.

Warschauer, M. (1995). Comparing face-to-face and electronic discussion in the second language classroom. CALICO journal, 7-26.

Wheeler, S., YEoMAnS, P., \& WHEElER, D. (2008). The good, the bad and the wiki: Evaluating student-generated content for collaborative learning. British journal of educational technology, 39(6), 987-995.

Witney, D., \& Smallbone, T. (2011). Wiki work: can using wikis enhance student collaboration for group assignment tasks?. Innovations in Education and Teaching International, 48(1), 101-110.

Yarrow, F., \& Topping, K. J. (2001). Collaborative writing: The effects of metacognitive prompting and structured peer interaction. British journal of educational psychology, 71(2), 261-282.

Zheng, B., Niiya, M., \& Warschauer, M. (2015). Wikis and collaborative learning in higher education. Technology, Pedagogy and Education, 24(3), 357-374.

Zurita, G., \& Nussbaum, M. (2007). A conceptual framework based on activity theory for mobile CSCL. British Journal of Educational Technology, 38(2), 211-235. 